\title{
Spatial and biocenotic trends in the water-mite fauna of small ponds
}

\author{
Ana I. Camacho \& Antonia G.-Valdecasas ${ }^{1}$ \\ Museo Nacional de Ciencias Naturales, Jose Gutierrez Abascal, 2, 28006-Madrid, Spain
}

Key words: temporary and permanent ponds, water mites, biotic trends

\begin{abstract}
Forty-one permanent and temporary ponds have been studied in a mountain range in the center of Spain. Abiotic variables are used to characterize the ponds. Spatial and biocenotic distribution patterns of macroinvertebrates with special reference to the water mite fauna are considered.
\end{abstract}

\section{Introduction}

Temporary and permanent stagnant waters are widely distributed around the world, but temporary waters are the least known, due, in part, to a supposed lack of economic interest. Most studies have dealt with the taxonomy of their inhabitants. For recent, more comprehensive approaches see HartlandRowe, 1972 and Wiggins et al., 1980.

Faunal diversity tends to be low, although some of the taxa are quite abundant. Nevertheless, within a restricted area, total faunal diversity is high, due to low repetitivity.

The stagnant waters of the sierra del Guadarrama, a mountain range in the center of Spain, have mainly received a systematic approach. Arévale $(1921,1931)$ deals with insect larvae and cladocera, Viets (1930) and G.-Valdecasas (1981) with water mites, Alvarez \& Selga (1967) with several taxa and Margalef (1947) gives a more ecological view. More recently, we have looked at these ponds from an insular model perspective (G.-Valdecasas et al., 1984).

The present paper tries to understand the spatial and biocenological patterns shown by pond taxa, especially water mites.

\footnotetext{
1 Order of authorship determined by the toss of a coin.
}

\section{Material and methods}

\section{Study area}

The sierra de Guadarrama is a mountain range in the center of Spain. Its highest point is Peñalara, at $2430 \mathrm{~m}$. The whole area is mainly gneissic. It consists of $5800 \mathrm{~km}^{2}$, arbitrarily delimited above $1000 \mathrm{~m}$ altitude.

The area was divided into quadrats of $5 \mathrm{~km}$ per side, and at least one pond was looked for in each quadrat. Out of 115 quadrats only 41 ponds were found (Fig. 1).

\section{Sampling procedure}

The sampling period extended from spring into summer, when the temporary nature of the ponds was confirmed.

The following physico-chemical variables were taken at sampling time: altitude, mean depth, surface, water and air temperature (mercury thermometer), $\mathrm{pH}$ with Merck indicator paper, hardness (Merck tritiplex), and alkalinity (Aquamerck Alkalinitat). The nature of the substrate and vegetation growths was also noted. Macroinvertebrates were sampled quali- and quantitatively (see G.Valdecasas et al., 1984). Samples were fixed with formalin in $4 \%$ and sorted in the laboratory. 


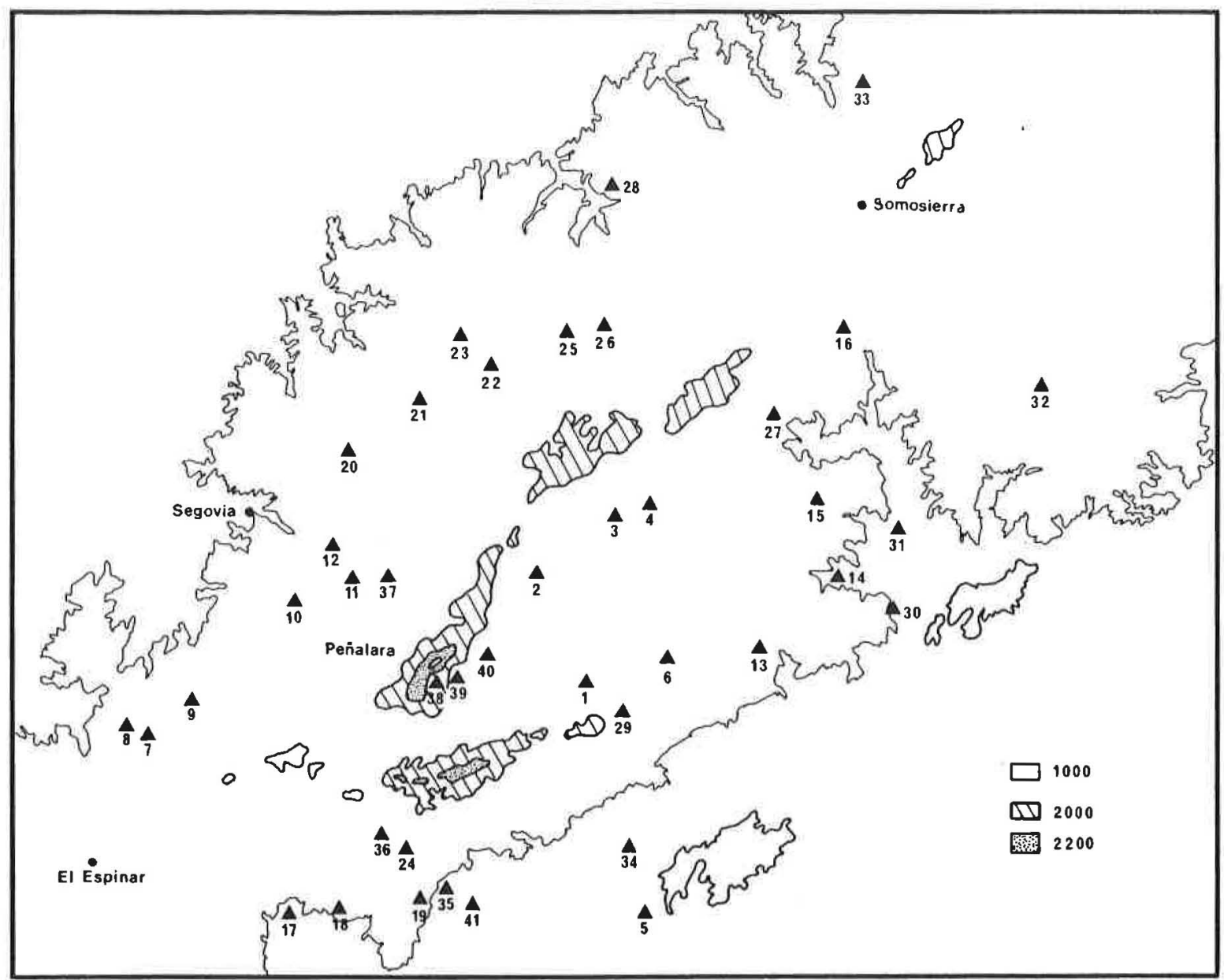

Fig. 1. Distribution of ponds in the Sierra de Guadarrama.

\section{Data analysis}

Data analysis was done with the BMDP Computer Package (Dickson, 1983). Programs 1M, 2M and 4M were used for cluster and principal component analysis (P.C.A.). Program 1M used a similarity matrix obtained by applying the Jaccard index to water mite faunal records in ponds. In this case, the average (U.P.G.M.A., see Sneath \& Sokal, 1973) was chosen for clustering. In program $2 \mathrm{M}$ we selected the $\mathrm{Eu}-$ clidean distance and the centroid algorithm for clustering. Principal components were obtained from the correlation matrix. Analysis of correspondence was done using Lebart \& Fenelons (1973) program.

\section{Results}

\section{Spatial trends}

The main purpose of this work has been to investigate the spatial and biocenotic trends in the pond communities of a mountain range. The search for the pattern of spatial directionality was carried out using the Wald-Wolfowitz, non-parametric run test (Siegel, 1956; Wratten \& Fry, 1980). Only two spatial directions, North-South and East-West, were analyzed for each of the following cases: the distribution pattern of ponds, water mites, calanoid and cyclopoid copepods and hemiptera, respectively. It was thought that each group would present a different kind of disperson and survival if the ponds dried up. Table 1 shows the values of quadrats, ponds and organisms used for the analysis, where $\overline{\mathrm{X}}$ is the mean 
Table 1. Spatial distribution trends of ponds and organisms. See text for explanation.

\begin{tabular}{|c|c|c|c|c|c|c|c|c|c|c|c|}
\hline \multicolumn{6}{|c|}{$E-W$ direction } & \multicolumn{6}{|c|}{$N-S$ direction } \\
\hline $\begin{array}{l}\text { No. } \\
\text { quadrat }\end{array}$ & $\begin{array}{l}\text { No. } \\
\text { ponds }\end{array}$ & $\begin{array}{l}\text { No. spp. } \\
\text { watermites }\end{array}$ & $\begin{array}{l}\text { No. spp. } \\
\text { calanoids }\end{array}$ & $\begin{array}{l}\text { No. spp. } \\
\text { cyclopoids }\end{array}$ & $\begin{array}{l}\text { No. spp. } \\
\text { Hemiptera }\end{array}$ & $\begin{array}{l}\text { No. } \\
\text { quadrat }\end{array}$ & $\begin{array}{l}\text { No. } \\
\text { ponds }\end{array}$ & $\begin{array}{l}\text { No. spp. } \\
\text { watermites }\end{array}$ & $\begin{array}{l}\text { No. spp. } \\
\text { calanoids }\end{array}$ & $\begin{array}{l}\text { No. spp. } \\
\text { cyclopoids }\end{array}$ & $\begin{array}{l}\text { No. spp. } \\
\text { Hemiptera }\end{array}$ \\
\hline 4 & 1 & 4 & 0 & 1 & 5 & 4 & 2 & 2 & 2 & 0 & 4 \\
\hline 6 & 1 & 3 & 0 & 3 & 5 & 4 & 1 & 3 & 3 & 4 & 0 \\
\hline 9 & 0 & 0 & 0 & 0 & 0 & 8 & 2 & 4 & 6 & 7 & 1 \\
\hline 10 & 4 & 17 & 8 & 18 & 5 & 10 & 4 & 6 & 4 & 3 & 2 \\
\hline 13 & 2 & 3 & 1 & 1 & 2 & 11 & 5 & 17 & 3 & 8 & 13 \\
\hline 12 & 5 & 4 & 2 & 5 & 7 & 11 & 3 & 12 & 5 & 10 & 6 \\
\hline 11 & 6 & 11 & 9 & 14 & 9 & 12 & 7 & 14 & 6 & 19 & 15 \\
\hline 11 & 7 & 7 & 8 & 10 & 11 & 10 & 1 & 0 & 0 & 0 & 3 \\
\hline 10 & 3 & 2 & 2 & 5 & 8 & 9 & 1 & 0 & 0 & 3 & 3 \\
\hline 9 & 2 & 7 & 0 & 2 & 11 & 9 & 4 & 8 & 3 & 7 & 10 \\
\hline \multirow[t]{8}{*}{8} & 7 & 24 & 5 & 13 & 12 & 6 & 3 & 3 & 0 & 6 & 9 \\
\hline & & & & & & 4 & 0 & 0 & 0 & 0 & 0 \\
\hline & $r=6$ & $r=7$ & $r=6$ & $I=6$ & $r=5$ & & $\bar{X}=0.349$ & $\overline{\mathrm{X}}=0.618$ & $\bar{X}=0.50$ & $\overline{\mathrm{X}}=0.311$ & $\widehat{\mathrm{X}}=0.772$ \\
\hline & $\mathrm{n}_{1}=5$ & $\mathrm{n}_{1}=5$ & $\mathrm{n}_{1}=4$ & $\mathrm{n}_{1}=4$ & $\mathrm{n}_{1}=8$ & & $r=8$ & $r=7$ & $r=4$ & $I=6$ & $r=9$ \\
\hline & $r_{c}=3$ & $r_{c}=3$ & $r_{c}=3$ & $I_{c}=3$ & $r_{c}=3$ & & & & & & \\
\hline & $\mathrm{n}_{2}=7$ & $\mathrm{n}_{2}=7$ & $\mathrm{n}_{2}=8$ & $\mathrm{n}_{2}=8$ & $\mathrm{n}_{2}=6$ & & $\mathrm{n}_{1}=7$ & $\mathrm{n}_{1}=6$ & $\mathrm{n}_{1}=4$ & $\mathrm{n}_{1}=8$ & $\mathrm{n}_{1}=7$ \\
\hline & & & & & & & $r_{c}=3$ & $r_{c}=3$ & $r_{c}=3$ & $r_{c}=3$ & $r_{c}=3$ \\
\hline & & & & & & & $\mathrm{n}_{2}=7$ & $\mathrm{n}_{2}=8$ & $\mathrm{n}_{2}=10$ & $\mathrm{n}_{2}=6$ & $\mathrm{n}_{2}=7$ \\
\hline
\end{tabular}


number of ponds or organisms per quadrat, $r$ is the number of runs and $n_{1}$ and $n_{2}$ the number of + and - signs respectively.

The null hypothesis, which states that the distribution of ponds and organisms in the area of study is random, could not be rejected in any case. That does not mean that random distribution or organisms has really been proved (Pielou, 1969).

This result is reinforced, as we will see below, when the faunal and geographic similarity between ponds is examined. Neighbouring ponds do not necessarily contain similar fauna.

\section{Abiotic/Biocenotic trend}

First we have analyzed whether there is a clear pattern of distribution of ponds in relation to abiotic variables. Figure 2 and Table 2 synthesize the values of the abiotic variables.

Two different analyses have been performed, one of classification and the other of ordination by P.C.A. Fig. 3 shows the resulting dendogram obtained from clustering with the following abiotic variables: pond surface and depth, hardness, alkalinity, $\mathrm{pH}$, altitude, vegetation and bottom type (this was codified as follows: muddy $=1$; stony/muddy $=2$; sandy $=3$ ). At an amalgamation distance of $1.2888,6$ cluster groups were obtained. Despite some minor disagreement, these groupings could be explained in terms of the temporary or permanent nature of the ponds. Minor disagreement could be due to the conflicting nature of certain ponds, that, in very dry years, could behave as temporary, and, in wet ones, as permanent ponds.

To clarify this hypothesis, a P.C.A. has been done using the following variables: altitude, area, depth, alkalinity, hardness and $\mathrm{pH}$. Table 3 shows the eigen values, the cumulative proportion of total variance for 6 factors, and contribution of variables to factors 1 and 2 . The first two factors explain more than $67 \%$ of the total variance. Figure 4 plots the ponds in the coordinated diagram formed by the first two factors. Looking at the contributions of variables to factors, alkalinity, $\mathrm{pH}$ and hardness have the highest contribution to factor 1 and depth, area and altitude to factor 2. If we eliminate $\mathrm{pH}$ and altitude for their lower variability, the coordinated space could be divided

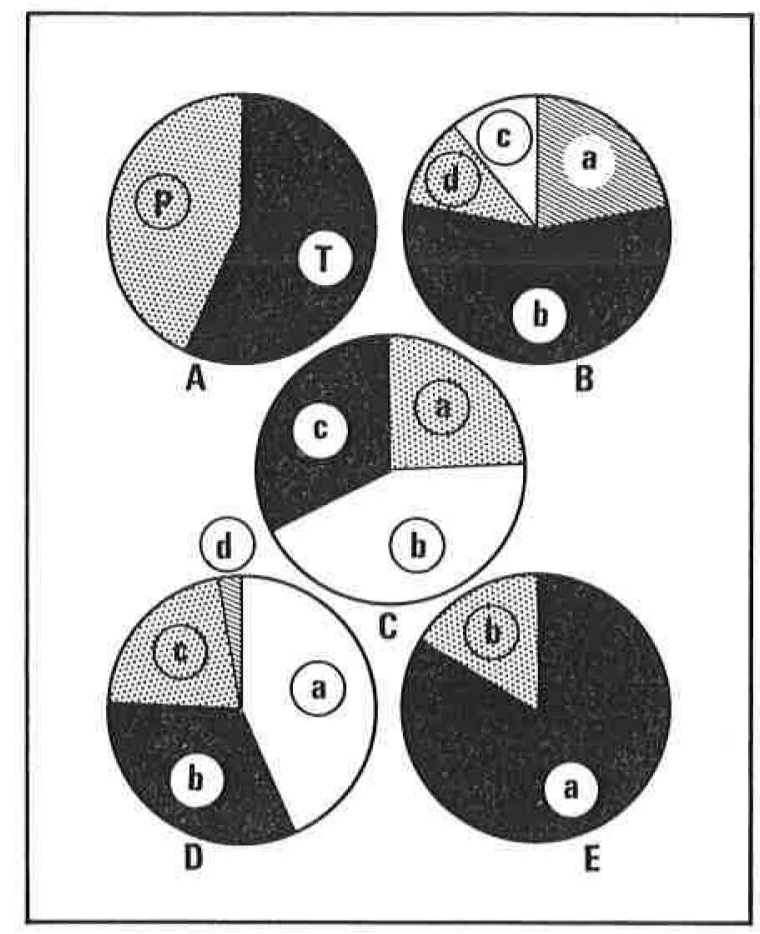

Fig. 2. Proportional contribution of different characteristic for the ponds of the Sierra de Guadarrama.

A- Pond type: Temporal $(\mathrm{T})=56.75 \%$; Permanent $(\mathrm{P})=43.35 \%$

B- Altitude: $900-1000 \mathrm{~m}$. (a) $=21.62 \%$; $1001-1200 \mathrm{~m}$. (b) $=56.76 \%$ $1201-1600 \mathrm{~m}$. (c) $=10.81 \%$; $1601 \quad$ (d) $=10.81 \%$

C- Alcalinity: $0.15-0.5$ (a) $=24.32 \%$;

$$
\begin{array}{ll}
0.6-1.2(\mathrm{~b})=43.24 \% \\
1.3 & \text { (c) }=32.43 \%
\end{array}
$$

D- Hardness: $0.5-2 \mathrm{mEq} / 1$ (a) $=43.24 \%$;

$$
\begin{array}{ll}
2.1-6 & \text { (b) }=32.43 \% \\
6.1-9 & \text { (c) }=18.91 \% \text {; }
\end{array}
$$

$\begin{array}{ll}9.1 & (d)=5.4 \% \\ 5.5-6.5(a)=83.78 \%\end{array}$

$6.6-7.5(b)=16.21 \%$

into a fourth area plane, where area I and II correspond to permanent ponds with low and high hardness and alkalinity, respectively. Area III and IV have temporary ponds with low and high hardness and alkalinity, respectively. It seems, then, that abiotic variables define ponds in terms of their temporary or permanent nature, although this pattern is not so well defined as to allow us to make a clear hierarchical classification. Although the extremes, the always permanent and temporary ponds, could be clearly distinguished, between them exists a continuum of alternatively temporary or permanent 
Table 2. Principal characteristics of the small water bodies of the Sierra de Guadarrama.

\begin{tabular}{|c|c|c|c|c|c|c|c|c|c|}
\hline $\begin{array}{l}\text { Ponds } \\
\text { (number) }\end{array}$ & $\begin{array}{l}\text { U.T.M. } \\
(30 T)\end{array}$ & $\begin{array}{l}\text { Altitude } \\
\text { (m) }\end{array}$ & Vegetation & Type & $\begin{array}{l}\text { Area } \\
\left(\mathrm{m}^{2}\right)\end{array}$ & $\begin{array}{l}\text { Depth } \\
(\mathrm{cm})\end{array}$ & $\begin{array}{l}\text { Alcalinity } \\
(\mathrm{mEq} / \mathrm{l})\end{array}$ & $\begin{array}{l}\text { Hardness } \\
\left({ }^{\circ} \mathrm{d}\right)\end{array}$ & $\mathrm{pH}$ \\
\hline 01 & V1296215 & 1740 & grass & temporary & 480 & 30 & 2.9 & 5.60 & 6.5 \\
\hline 02 & VL269293 & 1150 & absent & temporary & 280 & 76 & 2.9 & 6.72 & 6.5 \\
\hline 03 & V1329335 & 1120 & absent & permanent & 280 & 300 & 1.5 & 8.40 & 6.5 \\
\hline 04 & VL342343 & 1120 & algae & temporary & 34 & 15 & 1.5 & 8.40 & 6.5 \\
\hline 05 & VL337058 & 940 & mixture & temporary & 140 & 43 & 1.4 & 6.16 & 6.5 \\
\hline 06 & VL358227 & 1280 & grass & temporary & 30 & 40 & 0.5 & 1.12 & 6.5 \\
\hline 07 & UL988191 & 1180 & grass & temporary & 4 & 24 & 2.6 & 8.96 & 7.2 \\
\hline 08 & UL975192 & 1160 & grass & temporary & 9 & 6 & 2.0 & 5.60 & 6.8 \\
\hline 09 & VL013208 & 1140 & mixture & permanent & 194 & 43 & 1.2 & 1.68 & 6.5 \\
\hline 10 & VL091275 & 1120 & algae & permanent & 167 & 30 & 0.8 & 1.12 & 6.4 \\
\hline 11 & VL132286 & 1120 & grass & temporary & 82 & 27 & 0.6 & 1.20 & 6.4 \\
\hline 12 & VL121315 & 1100 & grass & temporary & 51 & 42 & 0.8 & 3.35 & 6.5 \\
\hline 13 & VL425241 & 1200 & algae & permanent & 29 & 16 & 0.7 & 2.80 & 6.5 \\
\hline 14 & VL484287 & 970 & grass & temporary & 27 & 7 & 1.0 & 3.36 & 6.5 \\
\hline 15 & V1 1460346 & 1160 & grass & temporary & 19 & 11 & 0.3 & 1.12 & 6.5 \\
\hline $16 \mathrm{~A}$ & VL486458 & 1150 & grass & temporary & 50 & 25 & 0.4 & 0.84 & 6.5 \\
\hline 17 & VL081056 & 980 & grass & temporary & 74 & 9 & 1.8 & 2.80 & 6.5 \\
\hline 18 & VL122056 & 1040 & grass & temporary & 16 & 47 & 0.7 & 29.12 & 6.5 \\
\hline 19 & VL186068 & 1000 & mixture & permanent & 65 & 31 & 0.5 & 1.68 & 6.5 \\
\hline 20 & VL141395 & 1100 & mixture & temporary & 30 & 22 & 0.8 & 1.68 & 6.5 \\
\hline 21 & VL178411 & 1175 & grass & temporary & 56 & 15 & 0.8 & 1.12 & 6.2 \\
\hline 22 & VL229440 & 1222 & grass & permanent & 28 & 23 & 1.0 & 5.04 & 7.2 \\
\hline 23 & VL207454 & 1130 & mixture & temporary & 148 & 19 & 0.4 & 1.68 & 6.4 \\
\hline 25 & VL287463 & 1200 & grass & temporary & 182 & 24 & 0.6 & 1.12 & 6.2 \\
\hline 26 & VL312465 & 1190 & grass & temporary & 600 & 21 & 0.4 & 1.68 & 6.5 \\
\hline 27 & VL521381 & 990 & grass & permanent & 230 & 41 & 1.0 & 2.24 & 6.0 \\
\hline 28 & VL327559 & 1020 & grass & permanent & 300 & 40 & 1.4 & 2.24 & 6.5 \\
\hline 32 & VL638414 & 1250 & grass & permanent & 800 & 52 & 0.4 & 1.12 & 6.0 \\
\hline 33 & VL492635 & 1060 & algae & permanent & 26 & 34 & 5.0 & 14.00 & 7.0 \\
\hline 34 & VL327102 & 900 & grass & temporary & 23 & 6 & 2.0 & 8.96 & 6.9 \\
\hline 35 & VL197073 & 990 & grass & temporary & 13 & 17 & 3.2 & 7.84 & 7.2 \\
\hline 36 & VL159111 & 1325 & mixture & permanent & 100 & 15 & 0.8 & 2.24 & 6.4 \\
\hline 37 & VL159288 & 1200 & absent & permanent & 35 & 44 & 0.6 & 2.80 & 6.4 \\
\hline 38 & VL195214 & 2021 & absent & permanent & 900 & 900 & 0.6 & 1.68 & 6.1 \\
\hline 39 & VL208214 & 1980 & grass & permanent & 25 & 20 & 0.4 & 1.12 & 6.0 \\
\hline 40 & VL221231 & 1900 & grass & permanent & 250 & 16 & 0.4 & 0.56 & 6.0 \\
\hline 41 & VL213067 & 950 & mixture & permanent & 250 & 400 & 1.2 & 2.80 & 6.5 \\
\hline
\end{tabular}

ponds, that depends more on the climate of the area than the characteristics of the pond.

\section{Water mite biocenotic trend}

Patterns of ordination and classification of the fauna have been obtained only of water mites, for which extensive data from the sierra already exist (G.Valdecasas \& Camacho, 1986). Table 4 shows pond water mite distribution in the sierra.
Prior to cluster analysis those ponds with only one species and those species found in only one pond were eliminated. Figure 5 shows the dendogram obtained through a similarity matrix. At a 50\% similarity level, 6 cluster groups are obtained. If they are analysed with regard to the temporary or permanent nature of the pond, it is found that there is no congruence in any one case. Permanent pond fauna remain in permanent ponds and temporary fauna in temporary ones.

Suspecting that fauna similarity could be due to 


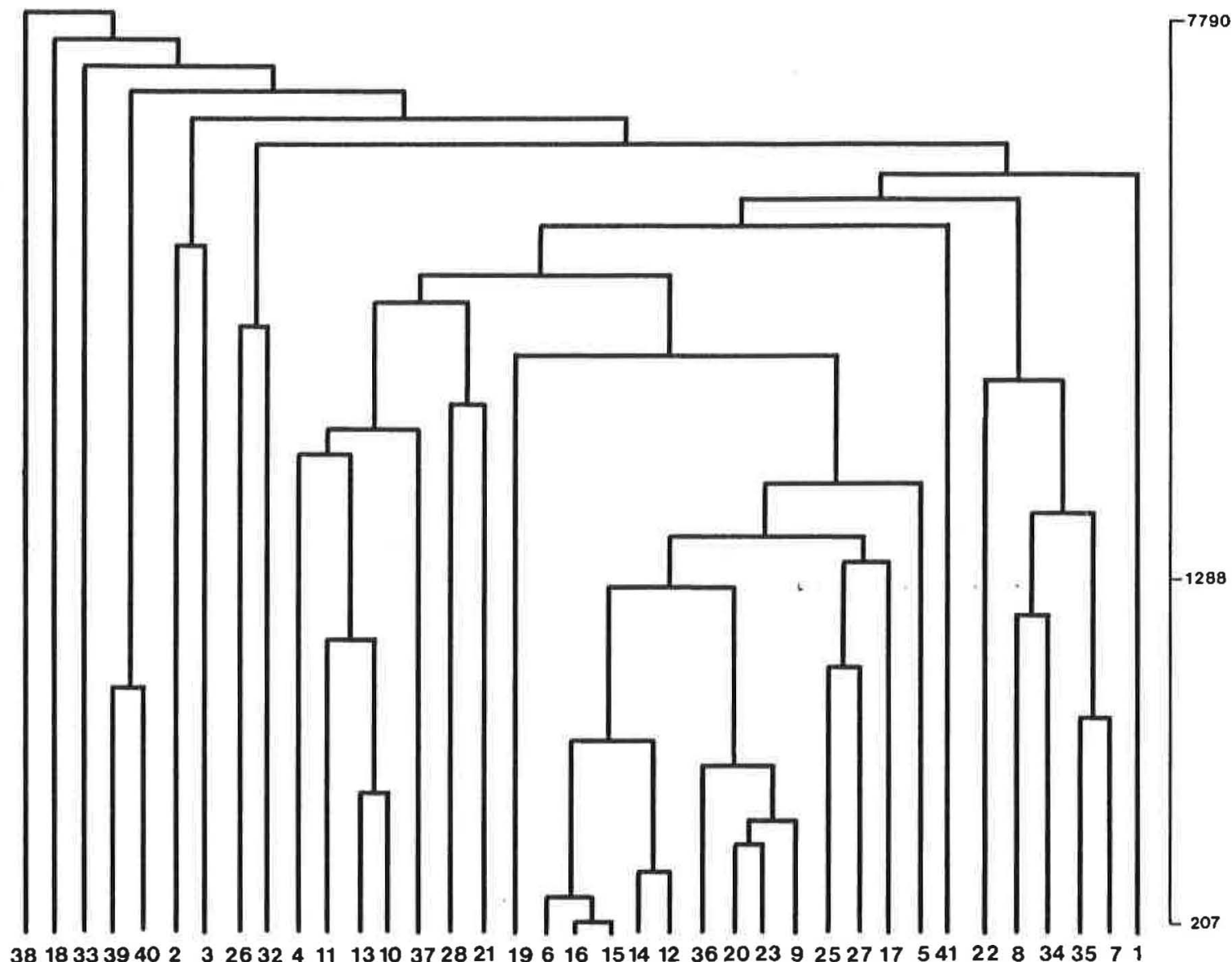

Fig. 3. Hierarchical classification of ponds, based on environmental variables.

the proximity of ponds rather than to their duration, a new classification was done, taking into account geographic locality and coordinates. The classification obtained, that clearly forms groups of neighbouring ponds, does not show any congruence with the previous faunal classification.

In order to take into account, at the same time, species and pond contribution to a multidimension-

Table 3. Eigen values for six factors obtained through a P.C.A.

\begin{tabular}{lll}
\hline Factor & Eigen values & $\begin{array}{l}\text { Cumulative proportion } \\
\text { of total variance }\end{array}$ \\
\hline 1 & 2.687957 & 0.447993 \\
2 & 1.368274 & 0.676039 \\
3 & 0.650225 & 0.784409 \\
4 & 0.584381 & 0.881806 \\
5 & 0.454958 & 0.957633 \\
6 & 0.254205 & 1.000000 \\
\hline
\end{tabular}

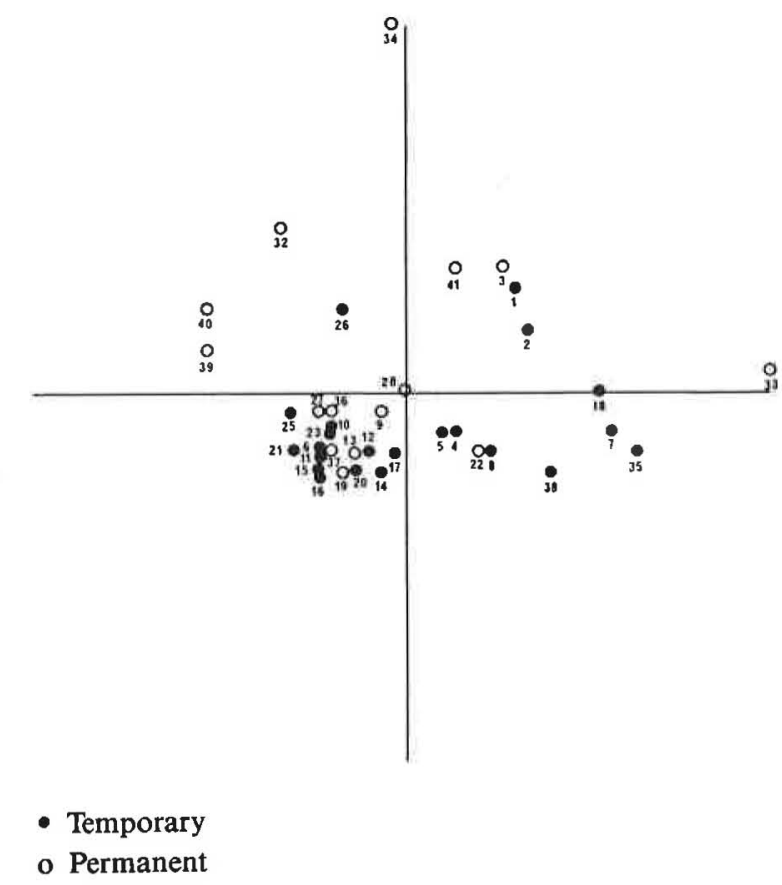

Fig. 4. Two factor projection of ponds based on a P.C.A. of the environmental variables: temporary; permanent. 
Table 4. Pond water mite distribution.

$122 \quad 3 \quad 4 \quad 5 \quad 6 \quad 7 \quad 8 \quad 8 \quad 9 \quad 101112131415161617181920212223242526272829303132333435363738394041$

Hydrachna globosa

Hydrachna rophaloidea

Eylais extendens

Eylais tantilla

Eylais hamata

Hydryphantes ruber

Thyas barbigera

Euthyas truncata

Diplodontus scapularis

Hydrodroma despiciens

Limnesia koenikei

Hygrobates longipalpis

Neumania deltoides

Piona nodata

Piona conglobata

Wettina podagrica

Tiphys ornatus

Tiphys latipes

Pionopsis lutescens

Arrenurus ancoriferus

Arrenurus distans

Arrenurus redrogensis

Arrenurus radiatus

Arrenurus szalayi

Arrenurus papillator

Arrenurus octagonus

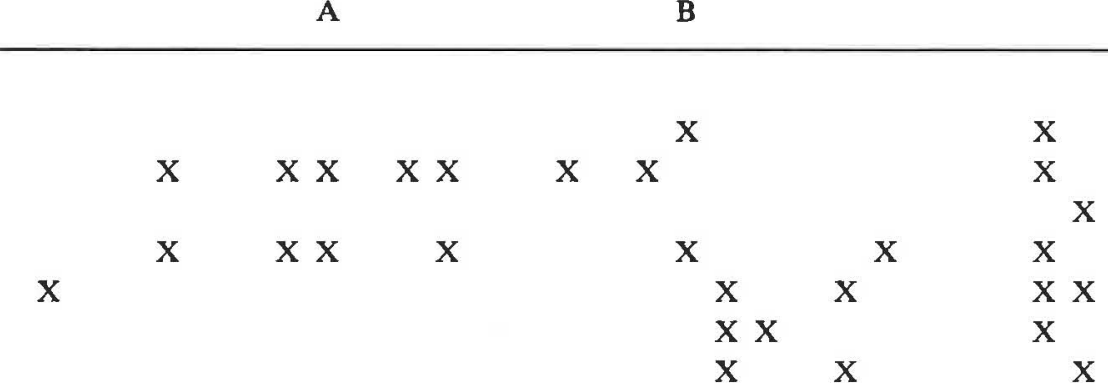

$\mathrm{X}$

$\mathrm{X} X \mathrm{X}$
$\mathrm{x}$

$\mathrm{X}$
$\mathrm{X} X$
$\mathrm{X}$

$\mathrm{X}$

$\mathrm{X}$

$\mathrm{X}$

$\mathrm{X}$

$\mathrm{X} \quad \mathrm{X}$

$\mathrm{X}$

$\mathrm{X}$

$\mathrm{X}$

$\mathrm{X}$

X X

$\mathrm{X}$

$\mathrm{X}$

$\mathrm{X}$

$\mathrm{X}$

$\mathrm{x}$

$\mathrm{X}$
$\mathrm{X}$

$\mathrm{X}$

$\mathrm{X} X$

X X

$\mathrm{X}$

$\mathrm{x}$

X 


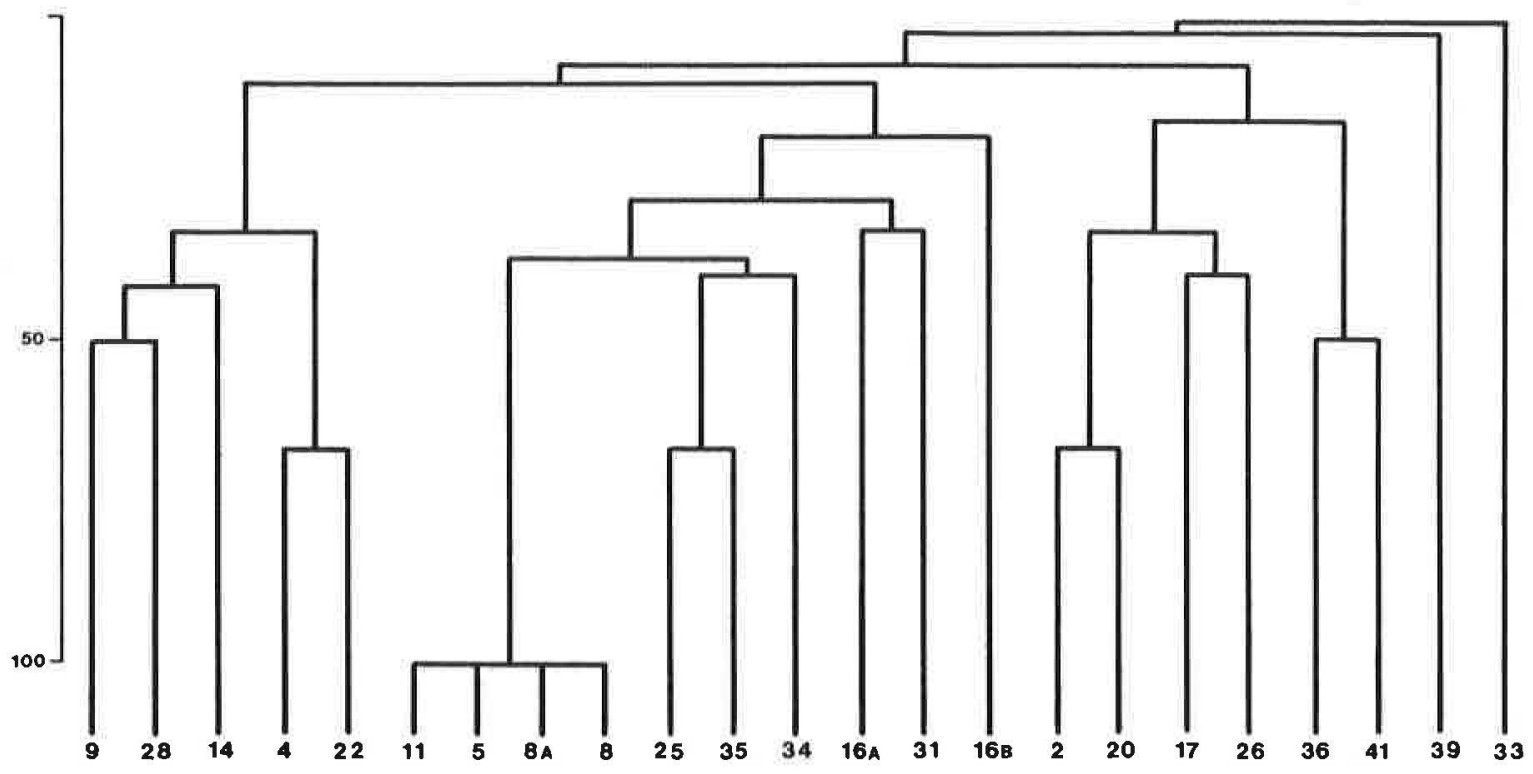

Fig. 5. Hierarchical classification of ponds based on faunal similarity.

Table 5. Ponds and species relative contributions to factor 1 and 2 of the correspondence analysis.

\begin{tabular}{|c|c|c|c|c|c|}
\hline & Factor 1 & Factor 2 & & Factor 1 & Factor 2 \\
\hline $\mathrm{C} 02$ & 0.100 & 0.434 & Hydrachna globosa (HYG) & 0.278 & 0.329 \\
\hline $\mathrm{CO4}$ & 0.001 & 0.078 & Hydrachna rophaloidea (HYR) & 0.317 & 0.026 \\
\hline $\mathrm{CO5}$ & 0.742 & 0.095 & Eylais extendens (EYE) & 0.705 & 0.019 \\
\hline $\mathrm{C} 08$ & 0.742 & 0.095 & Eylais hamata $(\mathrm{EYH})$ & 0.606 & 0.014 \\
\hline $\mathrm{C} 09$ & 0.013 & 0.046 & Eylais tantilla (EYT) & 0.015 & 0.077 \\
\hline $\mathrm{C} 10$ & 0.312 & 0.099 & Hydryphantes ruber (HYU) & 0.185 & 0.112 \\
\hline $\mathrm{C} 11$ & 0.742 & 0.095 & Thyas barbigera (THB) & 0.167 & 0.055 \\
\hline C14 & 0.085 & 0.011 & Euthyas truncata (EUT) & 0.042 & 0.257 \\
\hline $\mathrm{C} 16$ & 0.593 & 0.012 & Diplodontus scapularis (DIS) & 0.009 & 0.036 \\
\hline $\mathrm{C} 17$ & 0.201 & 0.028 & Hydrodroma despiciens (HYD) & 0.096 & 0.062 \\
\hline $\mathrm{C} 18$ & 0.109 & 0.073 & Limnesia koenikei (LIK) & 0.088 & 0.288 \\
\hline C19 & 0.115 & 0.067 & Hygrobates longipalpis (HYL) & 0.012 & 0.034 \\
\hline $\mathrm{C} 20$ & 0.102 & 0.333 & Neumania deltoides (NED) & 0.088 & 0.288 \\
\hline $\mathrm{C} 21$ & 0.153 & 0.054 & Piona nodata (PIN) & 0.001 & 0.465 \\
\hline $\mathrm{C} 22$ & 0.061 & 0.341 & Piona conglobata (PIC) & 0.012 & 0.034 \\
\hline $\mathrm{C} 25$ & 0.088 & 0.130 & Wettina podagrica (WEP) & 0.007 & 0.009 \\
\hline $\mathrm{C} 26$ & 0.082 & 0.300 & Tiphys ornatus (TIO) & 0.001 & 0.191 \\
\hline $\mathrm{C} 28$ & 0.091 & 0.005 & Tiphys latipes (TIL) & 0.163 & 0.011 \\
\hline $\mathrm{C} 30$ & 0.312 & 0.099 & Pionopsis lutescens (PIL) & 0.063 & 0.234 \\
\hline C31 & 0.141 & 0.005 & Arrenurus ancoriferus (ARA) & 0.009 & 0.036 \\
\hline $\mathrm{C} 33$ & 0.016 & 0.122 & Arrenurus distans (ARD) & 0.109 & 0.244 \\
\hline C34 & 0.036 & 0.000 & Arrenurus rodrigensis (ARR) & 0.149 & 0.270 \\
\hline $\mathrm{C} 35$ & 0.062 & 0.001 & Arrenurus radiatus (ART) & 0.149 & 0.270 \\
\hline $\mathrm{C} 36$ & 0.310 & 0.169 & Arrenurus szalayi (ARS) & 0.149 & 0.270 \\
\hline C39 & 0.028 & 0.091 & Arrenurus papillator (ARP) & 0.000 & 0.190 \\
\hline $\mathrm{C} 41$ & 0.482 & 0.301 & Arrenurus octagonus (ARO) & 0.278 & 0.084 \\
\hline
\end{tabular}




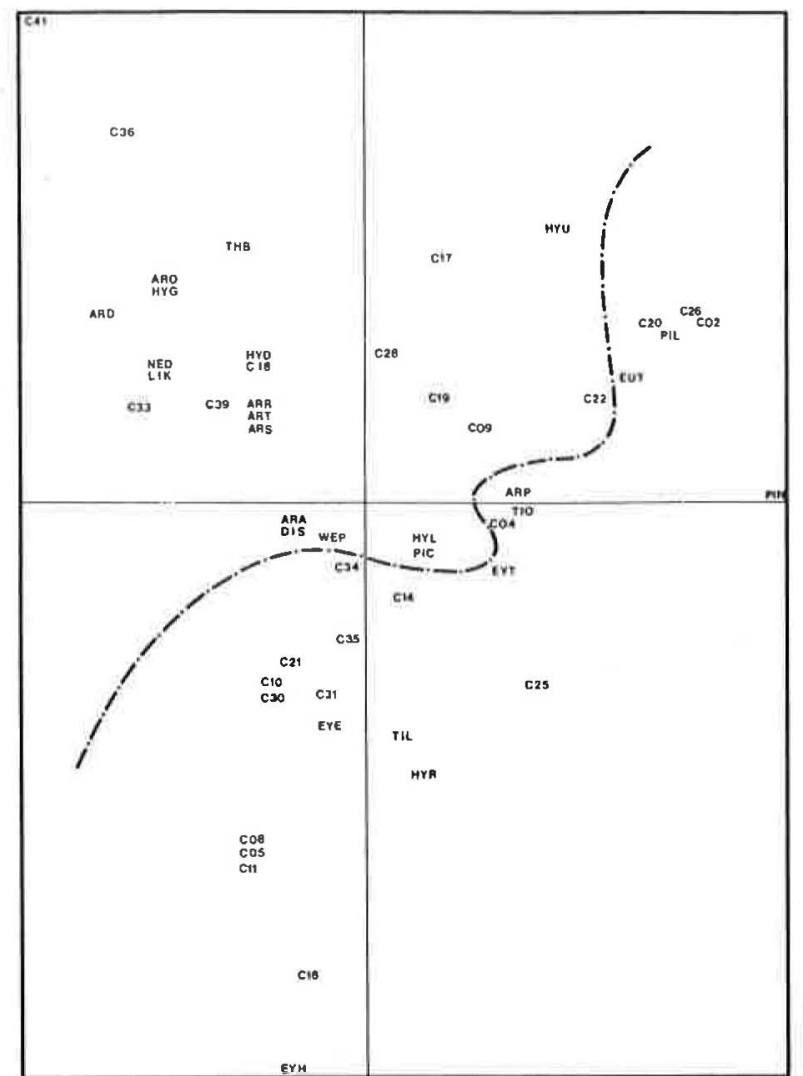

Fig. 6. Two factors projection of the analysis of correspondence between water mite species and ponds. Vertical axis interpreted in terms of the temporary-permanent nature of ponds. Horizontal axis interpreted in terms of the early-late development of water mites.

al, complementary space, we have done a correspondence analysis for the water mite fauna. Table 5 includes the factor contributions for ponds and water mite species. The first three factors account for $46 \%$ of the total variance $(I=20.28 \%$; II $=14.62 \%$; $\mathrm{III}=12.16 \%$ ). Figure 6 shows the scatter diagram of the first two factors, and our interpretation of the ordination scheme.

Ponds ordinate in the first factor mainly with respect to their permanent or temporary nature. Those that belong more clearly to one or other of these categories have the highest contribution to this factor. Factor two does not have a clear interpretation in terms of pond ordination.

The species with the highest contribution to factor I are, on the one hand: Hydrachna rhopaloidea, Arrenurus octagonus and Hydrachna globosa and, at the other extreme, the species of the genus Eylais: $E$. extendens and E. hamata predominate. Factor II is strongly influenced at its positive extreme by Hydrachna globosa, Arrenurus octagonus, Limnesia Koenikei and Neumania deltoides. The highest contributions belong to the negative part of the projected factor, with Piona nodata, Euthyas truncata and Pionopsis lutescens being the most important species.

A detailed study of species contribution to factors I and II reveals a vertical gradient of temporary versus permanent species, and an early versus late gradient in the horizontal direction. Eylais extendens and $E$. hamata predominate in temporary waters but Hydrachna globosa, H. rophaloidea and Arrenurus octagonus are typical of permanent waters. Those species between Pionopsis lutescens and Piona nodata and Hydracna globosa, Arrenurus octagonus, Limnesia koenikei and Neumania deltoides ordinate in an early-late fashion.

On the whole, the early species tend to be present in temporary waters and the gradient moves toward permanent waters where the 'later' species predominate.

\section{Discussion}

The irregular distribution of ponds through the area of study, although not completely rejecting the random null hypothesis, does not allow us to accept it. Not every quadrat was searched completely for the total number of ponds they contained. Once a pond was located in a quadrat, the search was stopped, and, unless some other pond in the quadrat was in sight, no more were included. In some areas, the distribution of the ponds studied reflects their accessibility, although not all were near a road or path.

The distribution of organisms in the ponds does not show any definite pattern. Even the proximity of ponds does not assure similarity in their fauna. This fact is a well-recognized one in the literature (Wiggins et al., 1981) of different kinds of organisms. In our case, several factors seem to combine to produce what should be a complex pattern. Even within the same group of organisms, different species have different ways of dispersing and enduring until the next cycle. Some of them survive in the same pond 
in a resting phase, and some leave the ponds when dry and return when they fill. What complicates the possibility of clarifying this unclear pattern, is that, as has been pointed out by several authors (Williams, 1983; Baltanás, 1985), during its annual cycle, a pond is a succesion of communities; different seasonal samplings for different ponds greatly increase the variability of their species populations at any given time than if compared for a whole annual cycle, and perhaps this could show a more understandable spatial pattern.

In the present state, our findings only strengthen the fact that, apparently, proximal ponds very frequently have a markedly different population.

Analyses of abiotic components have shown the relative independence of the chemical variables from the morphological ones, that is, area, depth and location (altitude). But these last are clearly related to the temporary or permanent nature of the ponds. In an area like the Sierra del Guadarrama, in some years a pond could be filled as late as December, but with snow, although it is more regularly filled by October with the first rains. Only clear extremes will dry up or retain water under very different sets of conditions. More intermediate ponds will shift to the permanent or temporary category, depending on that year's climatic conditions.

Although the physico-chemical variables studied have been few, it seems that only organisms, that can integrate long, enduring patterns in their life strategies, will be useful to discriminate and classify those ponds that in a short sampling period, (which could be a few years!), do not behave in a definite way.

Water mite taxocenosis is an example of this last assertion. One source of variability is the different life patterns. Species living in temporary ponds show two different strategies: overwintering in the dry pool basin mainly as egg or larvae, but in some species with nymphal and adult resistant states, and spring migrants to temporary ponds from permanent ones. Species of the family Hydryphantidae (Genus Hydryphantes, Euthyas and Thyas belong to it), F. Pionidae (G. Piona and Tiphys) and Arrenuridae (G. Arrenuridae) use the first strategy, and F. Eylaidae (G. Eylais) and F. Hydrachnidae (G. Hydrachna) show the second strategy (Wiggins et al., 1980).

Temporary ponds of the Sierra de Guadarrama are typical, autumnal pools, filling in October-November and drying up at the beginning of July. Neither of the two strategies makes any difference to the area under consideration.

What does make a difference is the time of maturity, and this is not necessarily correlated with species strategy but with pond nature. Those species living in temporary ponds tend to be adult early in the year: Piona nodata, Pionopsis lutescens, Euthyas truncata, Eylais extendens, $E$. hamata and $E$. tantilla. Those living in permanent water reach maturity mainly by July-August: Neumania deltoides, Limnesia koenikei, Hydrachna globosa and the Arrenurus species, excluding $A$. papillator.

Some species can live in temporary or permanent ponds. Hydryphantes species that have deutonymph and adult resistant states, depending on weather conditions, could overlap with those species typical of permanent water bodies.

In conclusion, lenthic water mite taxocenosis of the Sierra de Guadarrama clearly segregates, depending on the permanent or temporary nature of their ponds. An early arrival to the adult state is associated with those species living in temporary waters while the eclosion is later for those species living in permanent ponds. The gap between these two categories is filled by those species that are able to survive in both environmental conditions.

\section{Summary}

The study of the spatial distribution of the ponds of a mountain range does not show any geographic trend. A similar non-especific pattern is shown by the groups of organisms tested: water mites, calanoid and cyclopoid copepods and hemiptera.

Data analysis of the physico-chemical variables taken from 41 ponds, point to the permanent or temporary nature of the ponds as the most important characteristic, in order to classify them in discrete groups. The same trend is observed when the analysis done is an ordination.

Water mite species distribution in the ponds of the mountain range corroborate this perspective with a clearer pattern: the importance of the permanent versus temporary nature of ponds in relation to their

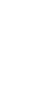


inhabitant organisms. An early-late trend of adult eclosion is related to pond type. Early species are favoured by temporary ponds and 'later' species by permanent ponds.

\section{Acknowledgements}

\section{Carlos Puch, Angel Baltanás and A. Fernández Lop} improved this paper. M. R. Miracle has indirectly made it possible. This research was supported by funds provided by the C.A.Y.C.I.T. (Grand No. 1530/82.)

\section{References}

Alvarez, J. \& D. Selga, 1967. Observaciones sobre invertebrados dulceacuicolas de los alrededores de Madrid. Bol. R. Soc. Española Hist. Nat. (Biol.) 65: 171-197.

Arevalo, C., 1921. Larvas planktonicas de Arquipteros de la Laguna de Peñalara. Real. Soc. Esp. Hist. Nat. 50: 169-172.

Arevalo, C., 1931. Los montruos de la Laguna de Peñalara. Cultura Segoviana, 1.

Baltanas, A., 1985. Variacion temporal de la fauna de Invertebrados de una charca temporal. Tesina de licenciatura. Univ. Autonoma Madrid, $194 \mathrm{pp}$.

Dickson, W. J., 1983. BMDP statistical software. University California Press, 734 pp.
G.-Valdecasas, A., 1981. Las hidracnelas de la sierra de Guadarrama: Taxonomïa, distribución y ecología. Tesis doctoral. Univ. Complutense Madrid, 532 pp.

G.-Valdecasas, A., A. F. Lop \& A. I. Camacho, 1984. Recurrence and equilibrium of temporal ponds of a mountain range in central spain. Arch. Hydrobiol. 102: 43-51.

G.-Valdecasas, A. \& A. I. Camacho, 1986. Las hidracnelas leniticas de la Sierra de Guadarrama. Graellsia XLII: 149-160.

Hartland-Rowe, R., 1972. The limnology of temporary waters and the ecology of Euphyllopoda. In: Clarck, R. B. \& R. Wootton (eds.), Essays in Hydrobiology: 15-31. Univ. Exeter.

Lebart, L. \& J. P. Fenelon, 1973. Statistique et informatique appliquees. Dunod, Paris.

Margalef, R., 1947. Datos para la hidrobiologia de la Sierra de Guadarrama. P. Inst. Biol. Apl. 6: 5-21.

Pielou, E. C., 1969. An introduction to mathematical ecology. Wiley-Interscience, New York, 286 pp.

Siegel, S., 1956. Nonparametric statistics for the behavioral sciences. Mcgraw-hill, New York, 312 pp.

Sneath, P. H. A. \& R. S. Sokalk, 1973. Numerical Taxonomy. W. H. Freeman \& Co, San Francisco, 573 pp.

Viets, K., 1930. Zur Kenntnis der Hydracarinen-Fauna von Spanien. Arch. Hydrobiol. 21: 175-240, 359-446.

Wiggins, G. B., R. Mackay \& I. M. Smith, 1980. Evolutionary and ecological strategies of animals in annual temporary pools. Arch. Hydrobniol. 58: 97-206.

Williams, D. D., 1983. The natural history of a neartic temporary pond in Ontario with remarks on continental variations in such habitats. Int. Rev. ges. Hydrobiol., 68: 239-253.

Wratten, S. D. \& G. L. A. Fry, 1980. Field and laboratory exercises in ecology. E. Arnold, London, 227 pp. 